\title{
Design of New Evaluation Model Based on Discrepancy Daiwi Asuri Sampad
}

\author{
Dewa Gede Hendra Divayana ${ }^{*}$, I Putu Wisna Ariawan ${ }^{2}$, Agus Adiarta ${ }^{3}$ \\ ${ }^{1}$ Department of IT Education,Universitas Pendidikan Ganesha, Jl. Udayana No. 11 Singaraja, Bali, 81116, Indonesia. \\ ${ }^{2}$ Department of Mathematics Education,Universitas Pendidikan Ganesha, Jl. Udayana No. 11 Singaraja, Bali, 81116, Indonesia. \\ ${ }^{3}$ Department of Electrical Education,Universitas Pendidikan Ganesha, Jl. Udayana No. 11 Singaraja, Bali, 81116, Indonesia.
}

\begin{abstract}
The effectiveness of flipped learning can be realized if the dominant aspects that become positive and negative inequalities are known from the beginning. Positive inequality is used to indicate aspects that support the successful flipped learning implementation. Negative inequality is used to indicate aspects that need attention for improvement in a better direction. The reality is very difficult to determine the aspects that are included in the positive and negative inequalities. Therefore, an innovation of the IT education evaluation model is needed to be able to solve those problems. The DIVAYANA model that is modified with the Discrepancy model and integrated with the Daiwi Sampad and Asuri Sampad concepts can be used as an innovation in the field of IT education evaluation. The main objective of this research was to show the design quality of the new evaluation model integrated with Balinese local wisdom. It is called the DIVAYANA model based on the Discrepancy Daiwi Asuri Sampad which can be used to evaluate the effectiveness of flipped learning implementation at IT vocational schools. This research was carried out by following the stages of the Borg and Gall development model. This research only focused on five stages from a total of ten development stages. Those stages included: 1) research and field data collection, 2) planning, 3) design development, 4) initial trials, and 5) revision of initial trials. The subjects involved in collecting field data were six people. The subjects involved in planning and designing of evaluation model were three people. The subjects involved in the initial trials were 44 people. Subjects involved in the revision of initial trial results were three people. Questionnaires were used to collect field data and conduct preliminary trials. The results of data collection from the initial trial results were analyzed using quantitative descriptive analysis techniques by percentage descriptive calculations. The results showed that the quality level of the DIVAYANA model design based on the Discrepancy Daiwi Asuri Sampad was $88.25 \%$. So that the design was included in the good category and can be used to determine the dominant aspects that become the positive and negative inequalities in flipped learning implementation. The contribution of this research to the field of education is to show the existence of a new evaluation model in the IT education field which can be used to determine the dominant aspects that become positive and negative inequalities in supporting the successful flipped learning implementation at IT vocational schools.
\end{abstract}

\section{Keywords:}

Design of New Evaluation Model;

DIVAYANA Model;

Discrepancy Model;

Daiwi Sampad;

Asuri Sampad;

Flipped Learning.

\section{1- Introduction}

The policy of Merdeka Belajar (freedom to learn) in Indonesia provides the widest possible freedom for students to create, express, and learn to understand things independently. This independent activity can be carried out through learning at school and outside the school through searching for information from digital platforms, social media, machine learning, or direct experience in the fields [1]. Efforts that can be made by schools in implementing this Merdeka Belajar policy are to determine the right learning models. One of the learning models that can be used to

*CONTACT: hendra.divayana@undiksha.ac.id

DOI: http://dx.doi.org/10.28991/ESJ-2022-06-01-013

(C) 2022 by the authors. Licensee ESJ, Italy. This is an open access article under the terms and conditions of the Creative Commons Attribution (CC-BY) license (https://creativecommons.org/licenses/by/4.0/). 
make it happen is flipped learning. Currently, flipped learning has been introduced as a learning model that can increase student's activity in the learning process. The presence of flipped learning requires students to be more active and independent in the learning process that is carried out at home and outside the classroom. Flipped learning encourages students to be able to search for learning resources freely via the internet or direct sources from the teacher through class discussions [2]. Class discussions are conducted to discuss problems that have not been resolved or have not been understood by students and whose sources are not available on the internet.

The current advancement of mobile technology provides space and opportunity to facilitate the flipped learning implementation in several senior high schools or vocational schools in Bali because most students at senior high schools or vocational schools level already have a smart-phone. Even in IT vocational schools, the existence of a smart-phone is needed to support the learning process. This is because some IT subjects (e.g., internet of things subject, mobile technology subject) require smart-phones for practice. Seeing those conditions, it is possible for carried out the flipped learning at IT vocational schools. Even though flipped learning is very possible to be implemented in all IT vocational schools in Bali, the facts show that there are still several IT vocational schools in suburban areas that are unable to carry out flipped learning optimally. It is caused by fundamental factors, such as the characteristics and minimum abilities of students in the use of technology, and students haven't adequate facilities to participate in flipped learning. Based on that situation, it is necessary to evaluate to determine the inequalities between the ideal standards for realizing flipped learning and the real conditions that occur in IT vocational schools in Bali. The values of inequalities make it easier to determine the right recommendations in realizing the effectiveness of the flipped learning implementation.

Seeing those problems and needs, an appropriate evaluation model is needed to evaluate the effectiveness of flipped learning at IT vocational schools in Bali, so that inequality can be found in the flipped learning implementation at IT vocational schools in Bali. Several educational evaluation models can be used to conduct general evaluations related to the implementation of flipped learning [3-5]. Those included: CIPP (Context-Input-Process-Product), Countenance, CSE-UCLA (Center for the Study of Evaluation-University of California in Los Angeles), Goal Oriented Evaluation Model, and others $[6,7]$. However, from those several educational evaluation models generally well-known, it wasn't to show the most dominant positive and negative inequalities in the flipped learning implementation. Therefore, one of the innovations needed and suitable to solve those problems is the DIVAYANA evaluation model based on Discrepancy Daiwi Asuri Sampad.

This evaluation model is a modification of the DIVAYANA evaluation model, the Discrepancy evaluation model, and Balinese local wisdom which comes from Hinduism (Daiwi Sampad and Asuri Sampad). The DIVAYANA (Description-Input-Verification-Action-Yack-Analysis-Nominate-Actualization) model is one of the educational evaluation models created by Dewa Gede Hendra Divayana which can be used to evaluate the effectiveness of ITbased learning at the vocational schools level by showing recommendations for priority improvements [8, 9]. The Discrepancy evaluation model is an educational evaluation model that shows gaps or differences between the evaluation standards that have been set and the evaluation results that occur in the fields [10, 11]. Daiwi Sampad is a Hindu religious philosophy that shows good deeds carried out by people, while Asuri Sampad is a bad deed that tends to be done by people $[12,13]$. Daiwi Sampad is good deeds from within humans, while Asuri Sampad is bad actions from within humans $[14,15]$.

The DIVAYANA model based on Discrepancy Daiwi Asuri Sampad provides appropriate recommendations in the form of aspects that show positive and negative inequalities that are most dominant in the flipped learning implementation at IT vocational schools in Bali. The interpretation of the positive inequality score refers to the Daiwi Sampad concept, while the interpretation of the negative inequality score refers to the Asuri Sampad concept. Positive inequality is used as the basis for maintaining the supporting aspects of the success of flipped learning, while negative inequality is used as the basis for making improvements toward obstacles in the flipped learning implementation.

Seeing the importance of the DIVAYANA evaluation model based on Discrepancy Daiwi Asuri Sampad, it is necessary to know more deeply related to the design of the evaluation model. Therefore, the research question is "How the design quality of the DIVAYANA evaluation model based on the Discrepancy Daiwi Asuri Sampad used to determine the most dominant positive and negative inequalities to realize the effectiveness of the implementation of flipped learning at IT vocational schools in Bali?"

Several related research results become the baseline of this research appearance. Zhao \& Sun [3] showed that the CIPP (Context-Input-Process-Product) model was able to be used to evaluate the flipped classroom curriculum in universities. The limitation of Zhao \& Sun's research was that it had not shown yet in detail the positive and negative inequalities that occur in the implementation of the flipped classroom curriculum. Sickle [16] showed evaluation activities to measure differences in students' achievement in following traditional learning compared to flipped classroom-based learning. The limitation of Sickle's research was that it had not shown yet the maximum difference or inequality that occurs between traditional learning compared to flipped classroom learning. Vogelsang \& Hoppe [17] showed that the FC (Flipped Classroom) model was used to evaluate the implementation of the flipped classroom by a 
measurement's focus on the speed of students in receive knowledge, knowledge acquisition, and lecturers' interaction (capability of lecturers to interact with students). The limitation of Vogelsang \& Hoppe's research was that it had not shown yet inequalities between the evaluation standards and the evaluation results obtained in the fields.

Shiau et al. [18] demonstrated the use of the SALG (Student Assessment of their Learning Gains) model to evaluate the implementation of "epidemiology introduction" learning based on the flipped classroom. The SALG model is used to evaluate flipped classrooms viewed from five components, included: teaching methods and class activities that facilitate learning, how to obtain knowledge topics, improve skills, overall students' enthusiasm for the subject or object being studied, and increase the capability of students to integrate information. The limitation of Shiau et al.'s research was that it had not shown yet fully explained about positive or negative inequalities that most dominantly occur in the implementation of "epidemiology introduction" learning using flipped classrooms. Bergfjord \& Heggernes [19] showed the results of an evaluation of students' experiences in using flipped classrooms. The limitations of Bergfjord \& Heggernes's research were that it had not shown yet a specific evaluation model used to conduct the evaluation and also it had not shown yet the most dominant inequality that occurs in the implementation of flipped classrooms viewed from students' experiences using the flipped classrooms.

Ha et al. [6] showed the use of the SDT (Self-Determination Theory) framework used to evaluate the flipped classroom approach in Asian universities viewed from five domains, included: a) increasing competency perceptions, b) foundations and platforms for deepening learning, c) flexibility and motivation become triggers for students to learn independently, d) strategies for giving the early facilitation and e) implementation strategies. The limitation of Ha et al.'s research was that it had not shown yet inequality between the evaluation results in the fields and the evaluation standards set.

Based on the problems that occur in the fields, the innovation initiated, and the limitations found from the results of previous studies, the researchers were interested in doing more in-depth research to be able to achieve the objectives of this research optimally. The purpose of this research was to determine the design quality of the DIVAYANA evaluation model based on Discrepancy Daiwi Asuri Sampad which was able to be used in providing recommendations in the form of aspects that showed the most dominant of positive and negative inequalities occurs in the implementation of flipped learning at IT vocational schools in Bali.

\section{2- Material and Methods}

\section{2-1-Research Approach and Research Method}

This research approach was the development. This research method was the Research \& Development method that used ten stages of the Borg and Gall development model [20,21]. Those ten stages can be seen completely in Figure 1.

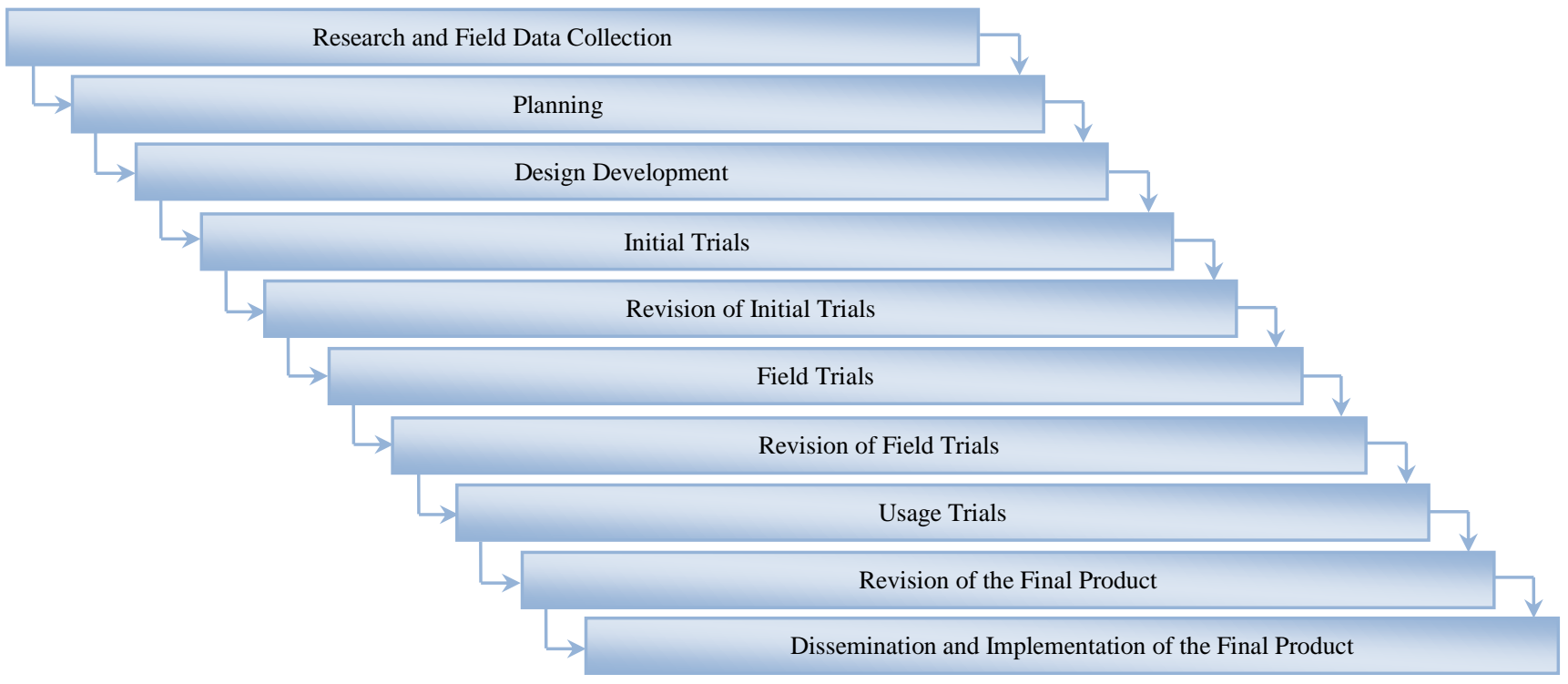

Figure 1. The Research Stages that Refer to Ten Stages of the Borg and Gall Development Model

Research in 2021 only was focused on five stages. Those stages included: 1) research and field data collection, 2) planning, 3) design development, 4) initial trials, and 5) revision of the initial trials. 


\section{2-2-Research Location, Sample, and Technique of Data Collection}

The research location was conducted at several IT vocational schools in six districts in Bali, such as Gianyar, Buleleng, Tabanan, Badung, Klungkung, and Denpasar. The reason for choosing research locations in several IT vocational schools was because in principle those schools had implemented flipped learning by adequate facilities and the characteristics of human resources were also technology literate. It's just that the flipped learning implementation is still not optimal.

The subjects in this research were determined using the purposive sampling technique. The parties involved in this research were determined from the initial and directly related to the flipped learning implementation at IT vocational schools in Bali. The subjects involved in field data collection were six people, included: one head of researcher, two research members, and three field assistants. The subjects involved in planning, designing the evaluation model, and revising the results of the initial trials were three people, included: one head of researcher, and two research members. The subjects involved in the initial trials of the evaluation model design were two informatics experts, two education experts, and 40 teachers of IT vocational schools in Bali.

The tools used in conducting field data collection and initial trials toward the evaluation model design were questionnaires. The numbers of questions in the field data collection questionnaires were eight items, while the numbers of questions in the questionnaires for the initial trials were 14 items. The assessment scores for each item used the Likert scale [22] which consists of five scoring options, included: score-5 (excellent category), score-4 (good category), score-3 (moderate category), score-2 (less category), and score-1 (poor category).

\section{2-3-The Formula for Determining the Positive and Negative Inequalities}

The formula used for the calculation process in determining the most dominant of positive and negative inequalities in the flipped learning implementation was the DIVAYANA formula. There are three equations in the DIVAYANA formula. Equation 1 is used to find the scores of weighted improvement, Equation 2 is used to find normalization scores, and Equation 3 is used to determine the scores of ranking. Those equations can be seen as follows [8,9]:

$\left(\mathrm{W}_{\text {Yack }}\right)_{\mathrm{j}}=\frac{\overline{\mathrm{x}_{\mathrm{j}}}}{\sum_{\mathrm{j}=1}^{\mathrm{n}} \overline{\mathrm{x}}_{\mathrm{j}}}$

Notes:

$\bar{x}=$ The average of weights given by the evaluators or experts through joint discussion;

$W_{\text {Yack }}=$ The average scores of weights improvement.

$\mathrm{D}_{\mathrm{i}}=\frac{\prod_{\mathrm{j}=1}^{\mathrm{n}} \mathrm{x}_{\mathrm{ij}}\left(\mathrm{W}_{\text {Yack }}\right)_{\mathrm{j}}}{\mathrm{m}}$

where: $\sum\left(\mathrm{W}_{\text {Yack }}\right)_{\mathrm{j}}=1$; and $\mathrm{i}=1,2,3, \ldots, \mathrm{n}$.

Notes:

$D=$ Vector $-\mathrm{D}$;

$x=$ Scores of assessment for each criterion;

$m=$ Total of all experts.

$\mathrm{R}_{\mathrm{i}}=\frac{\mathrm{D}_{\mathrm{i}}}{\sum_{\mathrm{i}=1}^{\mathrm{n}} \mathrm{D}_{\mathrm{i}}}$

Notes:

$D=$ Vector-D;

$R=$ Vector $-\mathrm{R}$.

\section{2-4-Data Analysis}

The quality of the DIVAYANA evaluation model design based on the Discrepancy Daiwi Asuri Sampad can be seen from the results of the data analysis obtained from the initial trials. The data had been collected from the initial trial results were analyzed using quantitative descriptive techniques using percentage descriptive calculations. The results of descriptive percentage calculations were used as the basis for interpreting the quality of this evaluation model design. The formula of descriptive percentage calculations can be seen as follows [23, 24].

$\mathrm{P}=\frac{\mathrm{f}}{\mathrm{N}} \times 100 \%$ 
Notes:

$\mathrm{P}=$ Descriptive Percentage;

$\mathrm{N}=$ Maximum number of scores;

$\mathrm{f}=$ Number of scores

The percentage results obtained from that formula were converted into the five's scale categorization. The quality percentage of 90 to $100 \%$ is in the excellent category, and 80 to $89 \%$ is in a good category based on the five's scale categorization, so there is no need to revise the evaluation model design. The quality percentage of 65 to $79 \%$ is in the moderate category, 55 to $64 \%$ is in the less category, and 0 to $54 \%$ is in the poor category based on the five's scale categorization, so it is necessary to revise toward the evaluation model design $[25,26]$.

\section{3- Results and Discussion}

At the stage of research and field data collection was obtained data related to the flipped learning implementation. Those data refer to several components of the DIVAYANA model. The DIVAYANA evaluation model consists of eight evaluation components, including the description component, the input component, the verification component, the action component, the yack component, the analysis component, the nominate component, and the actualization component $[8,9]$. Some of the data related to the description component, including 1) data of cause indicators for the flipped learning implementation at IT vocational schools in Bali, 2) data of indicators that become obstacles in the flipped learning implementation at IT vocational schools in Bali. Some of the data related to the input component were data about several solution alternatives to the obstacles in flipped learning implementation. Data related to the verification component, including 1) data of success standards for the flipped learning implementation at IT vocational schools in Bali, 2) data of suitability between the success standards compared with solution alternatives to obstacles. Some of the data related to the Action component were data of positive and negative inequalities that occur in the flipped learning implementation at IT vocational schools in Bali. Data related to the Yack component, including 1) data about the opinion of experts, 2) data of weights given by experts on each success standard of flipped learning. Some of the data related to Analysis, Nominate, and Actualization components were not shown at the stage of research and field data collection. Those data were shown at the stage of initial trials of the evaluation model design.

Table 1. Indicators of the causes of the flipped learning implementation at IT vocational schools in Bali

\begin{tabular}{ll}
\hline Indicators & \multicolumn{1}{c}{ Causes } \\
\hline Indicator-1 & The policy of Merdeka Belajar (freedom to learn) \\
Indicator-2 & Policies and regulations of the headmaster \\
Indicator-3 & Support of the school committee \\
Indicator-4 & The readiness of supporting facilities and infrastructure for flipped learning \\
Indicator-5 & The readiness of human resources \\
Indicator-6 & The readiness of material contents \\
Indicator-7 & Availability of budget \\
Indicator-8 & Internet access stability \\
\hline
\end{tabular}

Based on Table 1, it can be seen eight indicators cause the flipped learning implementation at IT vocational schools, especially in Bali. Generally, those indicators are related to the policies or rules for implementing flipped learning, support from stakeholders, funding readiness, facilities readiness, and human resources are involved in its implementation.

Table 2. Obstacles of the flipped learning implementation at IT vocational schools in Bali

\begin{tabular}{cl}
\hline Codes of Obstacles & \multicolumn{1}{c}{ Description of Obstacles } \\
\hline Obstacle-1 & The lack of understanding of the school community about the policy of Merdeka Belajar \\
Obstacle-2 & The inconsistency of policies and regulations made by the Headmaster in the implementation of the Merdeka Belajar policy \\
Obstacle-3 & Limitations of software and hardware supporting the flipped learning \\
Obstacle-4 & The un-preparedness of the manager's ability of flipped learning platforms \\
Obstacle-5 & The un-preparedness of the user's ability to operate the flipped learning \\
Obstacle-6 & Limitations of interesting material contents \\
Obstacle-7 & Limitations of budget \\
Obstacle-8 & Unstable internet access \\
\hline
\end{tabular}

Based on Table 2, it can be seen eight obstacles cause the non-optimal flipped learning implementation at IT vocational schools, especially in Bali. Those obstacles occur because of the discrepancy between the reality and standard indicators cause the flipped learning implementation shown in Table 1 previously. 
Table 3. Alternatives of solving obstacles for the flipped learning implementation at IT vocational schools in Bali

\begin{tabular}{cl}
\hline Codes of Alternatives & \multicolumn{1}{c}{ Description of Alternatives } \\
\hline Alternative-1 & Dissemination of the Merdeka Belajar policy to school community \\
Alternative-2 & Adjustment of school's policies and regulations with government policies \\
Alternative-3 & Maximum preparation of software and hardware for supporting the flipped learning \\
Alternative-4 & Prepare the ability of managers to be able to maintain the flipped learning platform optimally and sustainability \\
Alternative-5 & Preparing user's skills so that they can operate flipped learning optimally \\
Alternative-6 & Prepare material contents that can attract students' interest to learn \\
Alternative-7 & Collect budgets optimally as needed \\
Alternative-8 & Prepare for stable internet access \\
\hline
\end{tabular}

Based on Table 3, it can be seen eight alternative solutions to solve the obstacles in the flipped learning implementation at IT vocational schools, especially in Bali. Those alternatives appear to provide a choice of effective solutions that can be used to solve the obstacles for implementing flipped learning shown in Table 2.

Table 4. Success standards for the flipped learning implementation at IT vocational schools in Bali

\begin{tabular}{cll}
\hline Codes of Standards & \multicolumn{1}{c}{ Description of Success Standards } & Percentage of Effectiveness \\
\hline Standard-1 & There are efforts to disseminate the policy of Merdeka Belajar & $\geq 92 \%$ \\
Standard-2 & The conformity of school's policies and regulations with government policies & $\geq 92 \%$ \\
Standard-3 & The readiness of software and hardware for supporting the flipped learning & $\geq 90 \%$ \\
Standard-4 & The readiness of the ability to manage the flipped learning platforms & $\geq 88 \%$ \\
Standard-5 & The readiness of users' ability to operate the flipped learning & $\geq 88 \%$ \\
Standard-6 & Availability of interesting material contents & $\geq 88 \%$ \\
Standard-7 & Availability of budget that suitable with needs & $\geq 85 \%$ \\
Standard-8 & Availability of stable internet access & $\geq 90 \%$ \\
\hline
\end{tabular}

Based on Table 4, it can be seen eight success standards for the flipped learning implementation in IT vocational schools, especially in Bali. Those success standards are very important as the basic reference in carrying out the calculation process to obtain positive and negative inequalities values. The minimum percentage of effectiveness standards is obtained from the average assessment results of all experts toward the success standards of flipped learning implementation.

Table 5. The conformity between solution alternatives compared with the success standards of the flipped learning implementation at IT vocational schools in Bali

\begin{tabular}{|c|c|c|c|}
\hline \multirow{2}{*}{ Alternative Codes of Solving Obstacles } & \multirow{2}{*}{ Codes of Success Standards } & \multicolumn{2}{|c|}{ Results of Verification } \\
\hline & & Unsuitable & Suitable \\
\hline Alternative-1 & Standard-1 & & $\sqrt{ }$ \\
\hline Alternative-2 & Standard-2 & & $\sqrt{ }$ \\
\hline Alternative-3 & Standard-3 & & $\sqrt{ }$ \\
\hline Alternative-4 & Standard-4 & & $\sqrt{ }$ \\
\hline Alternative-5 & Standard-5 & & $\sqrt{ }$ \\
\hline Alternative- 6 & Standard-6 & & $\sqrt{ }$ \\
\hline Alternative-7 & Standard-7 & & $\sqrt{ }$ \\
\hline Alternative-8 & Standard-8 & & $\sqrt{ }$ \\
\hline
\end{tabular}

Based on Table 5, it can be seen a verification process carried out by experts to check the conformity between solution alternatives and the success standards of flipped learning implementation. If there is a suitable between the alternative and the standard, the expert will put a checkmark in the "Suitable" column. Conversely, if there is an unsuitable, the expert will put a checkmark in the "Unsuitable" column.

Based on Table 6, it can be seen that there are positive and negative inequalities calculations. The positive and negative inequalities scores are obtained from the deviation between the percentage of respondents' perceptions and the minimum percentage of the effectiveness standards. If the score from the deviation calculations is positive, then the score is placed in the positive inequality column. If the score from the deviation calculations is negative, then the score 
is placed in the negative inequality column. Even though in reality the score from the deviation calculations is negative, but that score is still written without the '-' (minus) sign at the negative inequality column. It is caused the score has been interpreted as negative based on the column where the score is placed (i.e., in the negative inequality column). The minimum percentage of the effectiveness standards in Table 6 comes from the data in Table 4. The percentage of respondents' perceptions is obtained from the results of perception assessments by respondents. The respondents involved in assessing perceptions of problem-solving alternatives in the flipped learning implementation were 40 teachers of IT vocational schools in Bali.

Table 6. Data about positive and negative inequalities that occur in the flipped learning implementation at IT vocational schools in Bali

\begin{tabular}{|c|c|c|c|c|}
\hline \multirow{2}{*}{ Alternative Codes of Solving Obstacles } & \multirow{2}{*}{$\begin{array}{l}\text { Minimum Percentage of the } \\
\text { Effectiveness Standards (\%) }\end{array}$} & \multirow{2}{*}{$\begin{array}{c}\text { Percentage of Respondents } \\
\text { Perceptions }(\%)\end{array}$} & \multicolumn{2}{|c|}{ Inequalities } \\
\hline & & & Positive & Negative \\
\hline Alternative-1 & 92.00 & 89.50 & 0.00 & 2.50 \\
\hline Alternative-2 & 92.00 & 92.50 & 0.50 & 0.00 \\
\hline Alternative-3 & 90.00 & 91.50 & 1.50 & 0.00 \\
\hline Alternative- 4 & 88.00 & 90.50 & 2.50 & 0.00 \\
\hline Alternative-5 & 88.00 & 87.50 & 0.00 & 0.50 \\
\hline Alternative- 6 & 88.00 & 86.00 & 0.00 & 2.00 \\
\hline Alternative-7 & 85.00 & 84.00 & 0.00 & 1.00 \\
\hline Alternative- 8 & 90.00 & 90.50 & 0.50 & 0.00 \\
\hline Average & & 89.00 & & \\
\hline
\end{tabular}

Table 7. Agreement data of experts' opinions

\begin{tabular}{ccl}
\hline No. & \multicolumn{1}{c}{ Experts } & \\
\hline 1 & Education Expert-1 & $\begin{array}{l}\text { Efforts to socialize the policy of Merdeka Belajar to all school communitieshad not been optimally } \\
\text { There had been adjustments to school regulations that refer to government policies }\end{array}$ \\
2 & Education Expert-2 & $\begin{array}{l}\text { There had been maximum efforts made by the school in preparing software and hardware to support the flipped } \\
\text { learning } \\
\text { The readiness of the manager's ability to maintain the flipped learning platforms were generally optimal and } \\
\text { needs to be implemented sustainability } \\
\text { Optimal efforts had been made to provide stable internet access }\end{array}$ \\
\hline
\end{tabular}

Based on Table 7, it can be seen that there are several opinions given by the experts as evidence of an agreement on the perception of the flipped learning implementation in IT vocational schools, especially in Bali. The conclusion of the agreement refers to qualitative data obtained from the results of interviews by experts to stakeholders in the flipped learning implementation at IT vocational schools in Bali.

Table 8. Data about average weights given by experts on each success standard of flipped learning

\begin{tabular}{ccccccc}
\hline \multirow{2}{*}{ Codes of Criteria } & \multicolumn{4}{c}{ Weights of Experts } & Average & $\begin{array}{c}\text { Improvement of Average Weights } \\
\left(\mathbf{W}_{\text {Yack }}\right)\end{array}$ \\
\cline { 2 - 5 } & Expert-1 & Expert-2 & Expert-3 & Expert-4 & & 0.12 \\
Standard-1 & 4 & 4 & 5 & 4 & 4.25 & 0.14 \\
Standard-2 & 5 & 5 & 5 & 5 & 5.00 & 0.11 \\
Standard-3 & 4 & 4 & 4 & 4 & 4.00 & 0.12 \\
Standard-4 & 4 & 5 & 4 & 4 & 4.25 & 0.13 \\
Standard-5 & 5 & 4 & 4 & 5 & 4.50 & 0.13 \\
Standard-6 & 5 & 4 & 5 & 4 & 4.50 & 0.13 \\
Standard-7 & 5 & 5 & 4 & 5 & 4.75 & 0.12 \\
Standard-8 & 4 & 4 & 4 & 5 & 4.25 & 1 \\
\hline
\end{tabular}

Based on Table 8, it can be seen that there are data on the results of improving the average weights ( $\left.\mathrm{W}_{\text {Yack }}\right)$ of each success standard in the flipped learning implementation. The results of the weights improvement depend on the weights given by experts to each standard. Referring to Equation 2, the $\mathrm{W}_{\text {Yack }}$ must be 1 . If it is valuable 1 , then the data can be said to be normal and ready to be used in the next calculation process. The data results from the improvement of the average weights are important in the calculation process to determine the most dominant aspect of positive and negative inequalities. 
At the planning stage were obtained information related to the job description, the number of human resources involved, and the time needed to complete this research. Complete information related to those things can be seen in Table 9.

Table 9. Details of the number of human resources, job descriptions, and time in the development of the DIVAYANA model design based on Discrepancy Daiwi Asuri Sampad

\begin{tabular}{clc}
\hline The Number of Human Resources & \multicolumn{1}{c}{ Job Descriptions } & Time (Day) \\
\hline 6 & Field data collection & 6 \\
3 & Making an evaluation model design & 6 \\
44 & Initial testing of the evaluation model design & 14 \\
3 & Revision of the initial trial results & 6 \\
\hline
\end{tabular}

Based on the data shown in Table 9, it appears that the total time required in developing this evaluation model design, starting from the stage of field data collection to revision of initial trials were 32 days. Three researchers and three field assistants were in charge of collecting data. Three researchers were tasked with making the evaluation model design and at the same time revising it after obtaining the initial trial results. A total of 44 respondents (four experts and 40 teachers) conducted initial trials of the evaluation model design.

At the stage of development was obtained the initial design form of the DIVAYANA model based on Discrepancy Daiwi Asuri Sampad. This design is formed by combining the DIVAYANA evaluation model and the Discrepancy evaluation model which is integrated with the Balinese local wisdom concept the Daiwi Sampad concept and the Asuri Sampad concept). That initial design form of the evaluation model can be seen in Figure 2. Based on Figure 2, the implementation of flipped learning at IT vocational schools in Bali can be evaluated using the DIVAYANA model based on Discrepancy Daiwi Asuri Sampad. There are eight components used to evaluate the flipped learning implementation, including the Description component, the Input component, the Verification component, the Action component, the Yack component, the Analysis component, the Nominate component, and the Actualization component. Evaluation of the causes and obstacles of the flipped learning implementation is evaluated in the Description component. In the Input component, evaluation is carried out on the aspects that become solution alternatives to the obstacles in implementing flipped learning. In the Verification component, evaluation is carried out on the aspects that become the success standards of the flipped learning implementation. In the Verification component also carried out checking the suitability of problem-solving alternatives with the success standards. The Action component evaluates the aspects that become positive and negative inequalities in the flipped learning implementation. The determination of this gap is based on the inequalities scores between the minimum percentage of the effectiveness standards and the percentage of respondents' perceptions. The process of calculating the inequality scores is carried out at the inequality analysis stage in the Discrepancy evaluation model. In the Yack component, perceptions or opinions are shared among the experts. In the Yack component also is conducted the calculation of the average weights given by the experts for each of the success standard aspects. In the Analysis component, the analysis process is carried out to prove the validity and truth of opinions or arguments that are mutually agreed upon by the experts. In the Nominate component is conducted the calculation of positive and negative inequalities that are most dominant in the flipped learning implementation. In the Actualization component is evaluated the actual implementation process of the most dominant positive inequality as the basis for maintaining the supporting aspects of the success of flipped learning implementation. In the Actualization component also is evaluated the actual implementation process of the most dominant negative inequality as a basis for revising aspects that become obstacles in the flipped learning implementation.

At the initial trials stage were conducted tests toward the DIVAYANA evaluation model design based on the Discrepancy Daiwi Asuri Sampad by 44 respondents. The complete results of the initial trials can be seen in Table 10. The data in Table 10 were obtained from data collection tools in the form of questionnaires consisting of 14 questions. Question-1 is about the existence of the Description component in the evaluation model. Question-2 is about the existence of the Input component in the evaluation model. Question-3 is about the existence of the Verification component in the evaluation model. Question-4 is about the existence of the Action component in the evaluation model. Question-5 is about the existence of the Yack component in the evaluation model. Question-6 is about the existence of the Analysis component in the evaluation model. Question-7 is about the existence of the Nominate component in the evaluation model. Question-8 is about the existence of the Actualization component in the evaluation model. Question-9 is about the existence of the Daiwi Sampad concept in the evaluation model. Question-10 is about the existence of the Asuri Sampad concept in the evaluation model. Question-11 is about the model's ability to measure positive inequality based on the Daiwi Sampad concept. Question-12 is about the model's ability to measure negative inequality based on the Asuri Sampad concept. Question-13 is about the accuracy of the DIVAYANA formula used in the nominate process in Nominate component. Question-14 is about the appropriateness of the decision-making process and recommendations. 


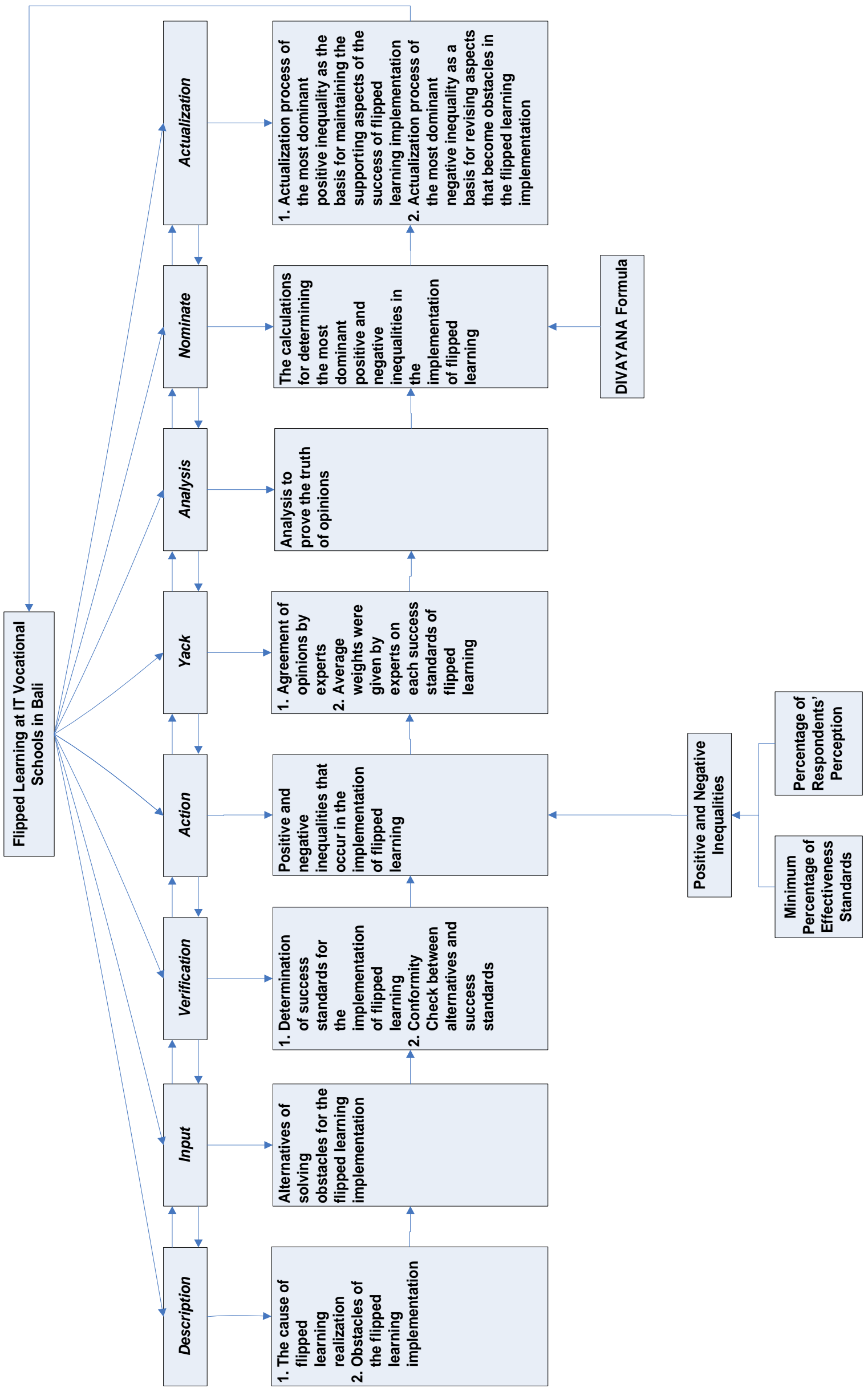

Figure 2. The initial design of the DIVAYANA model based on Discrepancy Daiwi Asuri Sampad 
Table 10. Results of initial trials toward the DIVAYANA model design based on the Discrepancy Daiwi Asuri Sampad

\begin{tabular}{|c|c|c|c|c|c|c|c|c|c|c|c|c|c|c|c|c|}
\hline \multirow{2}{*}{ Respondents } & \multicolumn{14}{|c|}{ Items- } & \multirow{2}{*}{$\sum$} & \multirow{2}{*}{ Percentage of Quality (\%) } \\
\hline & 1 & 2 & 3 & 4 & 5 & 6 & 7 & 8 & 9 & 10 & 11 & 12 & 13 & 14 & & \\
\hline Respondent-1 & 4 & 4 & 5 & 4 & 4 & 5 & 4 & 4 & 5 & 4 & 4 & 4 & 4 & 4 & 59 & 84.29 \\
\hline Respondent-2 & 4 & 5 & 4 & 5 & 4 & 4 & 5 & 4 & 4 & 5 & 5 & 4 & 4 & 4 & 61 & 87.14 \\
\hline Respondent-3 & 5 & 4 & 5 & 4 & 4 & 5 & 4 & 4 & 5 & 4 & 5 & 4 & 5 & 4 & 62 & 88.57 \\
\hline Respondent-4 & 4 & 4 & 5 & 4 & 5 & 4 & 5 & 5 & 4 & 4 & 4 & 5 & 4 & 5 & 62 & 88.57 \\
\hline Respondent-5 & 5 & 4 & 4 & 5 & 4 & 4 & 5 & 4 & 4 & 4 & 5 & 4 & 5 & 4 & 61 & 87.14 \\
\hline Respondent- 6 & 5 & 4 & 5 & 4 & 4 & 5 & 4 & 4 & 4 & 5 & 4 & 4 & 4 & 4 & 60 & 85.71 \\
\hline Respondent-7 & 5 & 5 & 4 & 5 & 4 & 4 & 5 & 4 & 5 & 4 & 4 & 5 & 4 & 5 & 63 & 90.00 \\
\hline Respondent- 8 & 4 & 4 & 4 & 5 & 4 & 5 & 4 & 5 & 4 & 5 & 4 & 5 & 5 & 4 & 62 & 88.57 \\
\hline Respondent-9 & 4 & 5 & 4 & 4 & 5 & 4 & 5 & 4 & 4 & 4 & 5 & 4 & 4 & 5 & 61 & 87.14 \\
\hline Respondent-10 & 4 & 4 & 4 & 5 & 4 & 4 & 5 & 5 & 4 & 5 & 4 & 4 & 5 & 4 & 61 & 87.14 \\
\hline Respondent-11 & 4 & 5 & 5 & 4 & 5 & 4 & 5 & 4 & 5 & 4 & 5 & 5 & 4 & 5 & 64 & 91.43 \\
\hline Respondent-12 & 4 & 4 & 5 & 4 & 5 & 5 & 4 & 5 & 4 & 4 & 5 & 4 & 5 & 4 & 62 & 88.57 \\
\hline Respondent-13 & 4 & 4 & 4 & 5 & 4 & 4 & 4 & 5 & 5 & 5 & 4 & 4 & 5 & 4 & 61 & 87.14 \\
\hline Respondent-14 & 5 & 4 & 5 & 4 & 4 & 5 & 4 & 5 & 4 & 5 & 5 & 5 & 4 & 5 & 64 & 91.43 \\
\hline Respondent-15 & 4 & 5 & 4 & 5 & 4 & 4 & 4 & 4 & 5 & 4 & 5 & 4 & 4 & 5 & 61 & 87.14 \\
\hline Respondent-16 & 4 & 4 & 5 & 4 & 4 & 4 & 4 & 5 & 4 & 5 & 4 & 4 & 4 & 4 & 59 & 84.29 \\
\hline Respondent-17 & 4 & 5 & 4 & 4 & 5 & 4 & 5 & 4 & 5 & 4 & 5 & 4 & 5 & 4 & 62 & 88.57 \\
\hline Respondent-18 & 5 & 4 & 5 & 5 & 4 & 5 & 4 & 4 & 4 & 5 & 4 & 4 & 4 & 4 & 61 & 87.14 \\
\hline Respondent-19 & 4 & 5 & 4 & 4 & 5 & 4 & 4 & 5 & 5 & 4 & 5 & 4 & 4 & 5 & 62 & 88.57 \\
\hline Respondent-20 & 4 & 4 & 5 & 4 & 4 & 5 & 4 & 4 & 4 & 4 & 5 & 5 & 4 & 5 & 61 & 87.14 \\
\hline Respondent-21 & 4 & 5 & 4 & 4 & 5 & 4 & 5 & 4 & 5 & 4 & 4 & 5 & 4 & 4 & 61 & 87.14 \\
\hline Respondent-22 & 5 & 4 & 5 & 5 & 4 & 5 & 4 & 5 & 4 & 5 & 5 & 4 & 5 & 5 & 65 & 92.86 \\
\hline Respondent-23 & 4 & 4 & 5 & 4 & 5 & 4 & 4 & 4 & 4 & 5 & 4 & 5 & 4 & 4 & 60 & 85.71 \\
\hline Respondent-24 & 4 & 5 & 4 & 4 & 4 & 5 & 4 & 5 & 4 & 5 & 4 & 4 & 5 & 4 & 61 & 87.14 \\
\hline Respondent-25 & 5 & 4 & 4 & 4 & 5 & 4 & 5 & 4 & 4 & 4 & 5 & 5 & 4 & 5 & 62 & 88.57 \\
\hline Respondent-26 & 4 & 5 & 5 & 5 & 4 & 5 & 4 & 5 & 5 & 4 & 5 & 4 & 4 & 5 & 64 & 91.43 \\
\hline Respondent-27 & 4 & 5 & 4 & 4 & 4 & 5 & 4 & 5 & 4 & 5 & 4 & 4 & 4 & 4 & 60 & 85.71 \\
\hline Respondent-28 & 4 & 5 & 4 & 5 & 4 & 5 & 4 & 5 & 5 & 4 & 4 & 4 & 5 & 5 & 63 & 90.00 \\
\hline Respondent-29 & 5 & 4 & 5 & 4 & 5 & 4 & 4 & 5 & 5 & 5 & 5 & 5 & 4 & 5 & 65 & 92.86 \\
\hline Respondent-30 & 4 & 5 & 4 & 5 & 4 & 5 & 5 & 4 & 4 & 4 & 5 & 4 & 4 & 4 & 61 & 87.14 \\
\hline Respondent-31 & 4 & 4 & 5 & 4 & 4 & 5 & 4 & 4 & 5 & 4 & 4 & 5 & 4 & 5 & 61 & 87.14 \\
\hline Respondent-32 & 4 & 5 & 4 & 5 & 5 & 4 & 5 & 5 & 4 & 5 & 5 & 4 & 5 & 4 & 64 & 91.43 \\
\hline Respondent-33 & 5 & 4 & 5 & 5 & 4 & 4 & 5 & 4 & 5 & 4 & 4 & 5 & 4 & 4 & 62 & 88.57 \\
\hline Respondent-34 & 5 & 4 & 5 & 5 & 4 & 4 & 4 & 4 & 5 & 4 & 5 & 4 & 5 & 4 & 62 & 88.57 \\
\hline Respondent-35 & 4 & 4 & 5 & 4 & 5 & 4 & 5 & 4 & 5 & 4 & 5 & 5 & 4 & 5 & 63 & 90.00 \\
\hline Respondent-36 & 5 & 4 & 4 & 5 & 4 & 4 & 4 & 5 & 4 & 5 & 4 & 4 & 4 & 4 & 60 & 85.71 \\
\hline Respondent-37 & 4 & 5 & 5 & 4 & 5 & 4 & 5 & 4 & 4 & 5 & 5 & 4 & 4 & 4 & 62 & 88.57 \\
\hline Respondent-38 & 4 & 5 & 4 & 4 & 5 & 5 & 4 & 5 & 5 & 4 & 4 & 4 & 4 & 5 & 62 & 88.57 \\
\hline Respondent-39 & 5 & 5 & 5 & 4 & 4 & 4 & 4 & 5 & 4 & 5 & 4 & 5 & 4 & 4 & 62 & 88.57 \\
\hline Respondent-40 & 5 & 4 & 4 & 5 & 4 & 5 & 5 & 5 & 5 & 4 & 5 & 4 & 4 & 4 & 63 & 90.00 \\
\hline Respondent-41 & 4 & 4 & 5 & 4 & 4 & 5 & 4 & 4 & 5 & 4 & 5 & 4 & 5 & 5 & 62 & 88.57 \\
\hline Respondent-42 & 4 & 5 & 4 & 4 & 5 & 4 & 4 & 5 & 4 & 4 & 4 & 4 & 4 & 4 & 59 & 84.29 \\
\hline Respondent- 43 & 5 & 4 & 5 & 5 & 4 & 5 & 5 & 4 & 5 & 5 & 5 & 4 & 5 & 4 & 65 & 92.86 \\
\hline Respondent-44 & 4 & 4 & 5 & 4 & 5 & 4 & 4 & 4 & 5 & 4 & 4 & 4 & 5 & 4 & 60 & 85.71 \\
\hline & & & & & Av & rage & & & & & & & & & & 88.25 \\
\hline
\end{tabular}


Some suggestions given by respondents when conducting initial trials were able to be used as a basis for making improvements to the design of the evaluation model being developed. Some of those suggestions can be seen in Table 11. The data in Table 11 shows the five suggestions given by the respondents. The five suggestions were important to be used as a basis for the revision process of the evaluation model design.

Table 11. Respondents' suggestions in the initial trials of the DIVAYANA model design based on the Discrepancy Daiwi Asuri Sampad

\begin{tabular}{ccl}
\hline No. & Respondents & Suggestions \\
\hline 1 & Respondent-4 & $\begin{array}{l}\text { The equations that exist in the DIVAYANA model need to be displayed in the design. } \\
\text { It is necessary to provide a dividing line to distinguish the processes that occur in the DIVAYANA evaluation model } \\
\text { and the Discrepancy evaluation model. } \\
\text { DIVAYANA and Discrepancy evaluation components need colouring differently so that it is clear the processes } \\
\text { carried out in each component. } \\
\text { The concepts of Daiwi Sampad and Asuri Sampad need to be inserted in determining positive and negative } \\
\text { inequalities. } \\
\text { The initial letter in the DIVAYANA evaluation component needs to be in bold so that it is known as the identity and } \\
\text { distinctive feature of the DIVAYANA evaluation model. }\end{array}$ \\
\hline
\end{tabular}

In addition to testing the model design, at this stage of initial trials also was conducted the accuracy test of the calculation process for determining the most dominant of positive and negative inequalities. It was carried out by referring to the Nominate component in the DIVAYANA model. The initial data were used to simulate the calculation process can be seen in Tables 12 and 13.

Table 12. Initial data were used for simulation the calculation process in determining the most dominant of positive inequality

\begin{tabular}{cccccccccc}
\hline \multirow{2}{*}{ Alternatives } & \multicolumn{7}{c}{ Standards } \\
\cline { 2 - 9 } & Standard-1 & Standard-2 & Standard-3 & Standard-4 & Standard-5 & Standard-6 & Standard-7 & Standard-8 \\
\hline Alternative-1 & 89.50 & 10.50 & 10.50 & 10.50 & 10.50 & 10.50 & 10.50 & 10.50 \\
Alternative-2 & 93.00 & 92.50 & 93.00 & 93.00 & 93.00 & 93.00 & 93.00 & 93.00 \\
Alternative-3 & 93.00 & 93.00 & 91.50 & 93.00 & 93.00 & 93.00 & 93.00 & 93.00 \\
Alternative-4 & 93.00 & 93.00 & 93.00 & 90.50 & 93.00 & 93.00 & 93.00 & 93.00 \\
Alternative-5 & 12.50 & 12.50 & 12.50 & 12.50 & 87.50 & 12.50 & 12.50 & 12.50 \\
Alternative-6 & 14.00 & 14.00 & 14.00 & 14.00 & 14.00 & 86.00 & 14.00 & 14.00 \\
Alternative-7 & 16.00 & 16.00 & 16.00 & 16.00 & 16.00 & 16.00 & 84.00 & 16.00 \\
Alternative-8 & 91.00 & 91.00 & 91.00 & 91.00 & 91.00 & 91.00 & 91.00 & 90.50 \\
\hline
\end{tabular}

Table 13. Initial data were used for simulation the calculation process in determining the most dominant of negative inequality

\begin{tabular}{ccccccccc}
\hline \multirow{2}{*}{ Alternatives } & \multicolumn{8}{c}{ Standards } \\
\cline { 2 - 8 } & Standard-1 & Standard-2 & Standard-3 & Standard-4 & Standard-5 & Standard-6 & Standard-7 & Standard-8 \\
\hline Alternative-1 & 89.50 & 87.00 & 87.00 & 87.00 & 87.00 & 87.00 & 87.00 & 87.00 \\
Alternative-2 & 7.50 & 92.50 & 7.50 & 7.50 & 7.50 & 7.50 & 7.50 & 7.50 \\
Alternative-3 & 8.50 & 8.50 & 91.50 & 8.50 & 8.50 & 8.50 & 8.50 & 8.50 \\
Alternative-4 & 9.50 & 9.50 & 9.50 & 90.50 & 9.50 & 9.50 & 9.50 & 9.50 \\
Alternative-5 & 87.00 & 87.00 & 87.00 & 87.00 & 87.50 & 87.00 & 87.00 & 87.00 \\
Alternative-6 & 84.00 & 84.00 & 84.00 & 84.00 & 84.00 & 86.00 & 84.00 \\
Alternative-7 & 83.00 & 83.00 & 83.00 & 83.00 & 83.00 & 83.00 & 84.00 \\
Alternative-8 & 9.50 & 9.50 & 9.50 & 9.50 & 9.50 & 9.50 & 9.50 \\
\hline
\end{tabular}

The data that is blocked in black and blue in Table 12 comes from the percentage of respondents' perceptions shown earlier in Table 6. The data that is un-blocked on the row of alternative-1 (10.50) is obtained by the following calculation: 100-89.50. The un-blocked data on the row of alternative-2 (93.00) is obtained by the following calculation: $92.50+0.50$. The score of 0.50 comes from the positive inequality score for alternative- 2 which is shown earlier in Table 6. The un-blocked data on the row of alternative-3 (93.00) is obtained by the following calculation: $91.50+1.50$. The score of 1.50 comes from the positive inequality score for alternative- 3 which is shown earlier in 
Table 6. The un-blocked data on the row of alternative-4 (93.00) is obtained by the following calculation: $90.50+$ 2.50. The score of 2.50 comes from the positive inequality score for alternative- 4 which is shown earlier in Table 6 . The un-blocked data on the row of alternative-5 (12.50) is obtained by the following calculation: 100-87.50. The unblocked data on the row of alternative-6 (14.00) is obtained by the following calculation: 100-86.00. The un-blocked data on the row of alternative-7 (16.00) is obtained by the following calculation: 100-84.00. The un-blocked data on the row of alternative- 8 (91.00) is obtained by the following calculation: $90.50+0.50$. The score of 0.50 comes from the positive inequality score for alternative- 8 which is shown earlier in Table 6.

The data that is blocked in blue and black in Table 13 comes from the percentage of respondents' perceptions shown earlier in Table 6. The data that is un-blocked on the row of alternative-1 (87.00) is obtained by the following calculation: $89.50-2.50$. The score of 2.50 comes from the negative inequality score for alternative- 1 which is shown earlier in Table 6. The un-blocked data on the row of alternative-2 (7.50) is obtained by the following calculation: $100-$ 92.50. The un-blocked data on the row of alternative-3 (8.50) is obtained by the following calculation: 100-91.50. The un-blocked data on the row of alternative-4 (9.50) is obtained by the following calculation: 100-90.50. The un-blocked data on the row of alternative-5 (87.00) is obtained by the following calculation: 87.50-0.50. The score of 0.50 comes from the negative inequality score for alternative- 5 shown earlier in Table 6 . The un-blocked data on the row of alternative-6 (84.00) is obtained by the following calculation: 86.00-2.00. The score of 2.00 comes from the negative inequality score for alternative- 6 which is shown earlier in Table 6 . The un-blocked data on the row of alternative-7 (83.00) is obtained by the following calculation: 84.00-1.00. The score of 1.00 comes from the negative inequality score for alternative-7 which is shown earlier in Table 6. The un-blocked data on the row of alternative-8 (9.50) is obtained by the following calculation: 100-90.50.

The calculation process of Vector-D is can be used to determine the normalization of positive inequality scores in the flipped learning implementation. The calculation process can be carried out using the initial data in Table 12, the data on the improvement of average weights shown previously in Table 8, and Equation 2 of the DIVAYANA formula. The calculation process of Vector-D can be seen completely as follows.

$$
\begin{aligned}
& \mathrm{D}_{1}=\frac{\left(89.50^{0.12}\right)\left(10.50^{0.14}\right)\left(10.50^{0.11}\right)\left(10.50^{0.12}\right)\left(10.50^{0.13}\right)\left(10.50^{0.13}\right)\left(10.50^{0.13}\right)\left(10.50^{0.12}\right)}{4}=3.41 \\
& \mathrm{D}_{2}=\frac{\left(93.00^{0.12}\right)\left(92.50^{0.14}\right)\left(93.00^{0.11}\right)\left(93.00^{0.12}\right)\left(93.00^{0.13}\right)\left(93.00^{0.13}\right)\left(93.00^{0.13}\right)\left(93.00^{0.12}\right)}{4}=23.44 \\
& \mathrm{D}_{3}=\frac{\left(93.00^{0.12}\right)\left(93.00^{0.14}\right)\left(91.50^{0.11}\right)\left(93.00^{0.12}\right)\left(93.00^{0.13}\right)\left(93.00^{0.13}\right)\left(93.00^{0.13}\right)\left(93.00^{0.12}\right)}{4}=23.42 \\
& \mathrm{D}_{4}=\frac{\left(93.00^{0.12}\right)\left(93.00^{0.14}\right)\left(93.00^{0.11}\right)\left(90.50^{0.12}\right)\left(93.00^{0.13}\right)\left(93.00^{0.13}\right)\left(93.00^{0.13}\right)\left(93.00^{0.12}\right)}{4}=23.39 \\
& \mathrm{D}_{5}=\frac{\left(12.50^{0.12}\right)\left(12.50^{0.14}\right)\left(12.50^{0.11}\right)\left(12.50^{0.12}\right)\left(87.50^{0.13}\right)\left(12.50^{0.13}\right)\left(12.50^{0.13}\right)\left(12.50^{0.12}\right)}{4}=4.02 \\
& \mathrm{D}_{6}=\frac{\left(14.00^{0.12}\right)\left(14.00^{0.14}\right)\left(14.00^{0.11}\right)\left(14.00^{0.12}\right)\left(14.00^{0.13}\right)\left(86.00^{0.13}\right)\left(14.00^{0.13}\right)\left(14.00^{0.12}\right)}{4}=4.43 \\
& \mathrm{D}_{7}=\frac{\left(16.00^{0.12}\right)\left(16.00^{0.14}\right)\left(16.00^{0.11}\right)\left(16.00^{0.12}\right)\left(16.00^{0.13}\right)\left(16.00^{0.13}\right)\left(84.00^{0.13}\right)\left(16.00^{0.12}\right)}{4}=5.02 \\
& D_{8}=\frac{\left(91.00^{0.12}\right)\left(91.00^{0.14}\right)\left(91.00^{0.11}\right)\left(91.00^{0.12}\right)\left(91.00^{0.13}\right)\left(91.00^{0.13}\right)\left(91.00^{0.13}\right)\left(90.50^{0.12}\right)}{4}=22.94
\end{aligned}
$$

The calculation process of Vector-D is can be used to determine the normalization of negative inequality scores in the flipped learning implementation. The calculation process can be carried out using the initial data in Table 13, the data on the improvement of average weights shown previously in Table 8, and Equation 2 of the DIVAYANA formula. The calculation process of Vector-D can be seen completely as follows:

$$
\begin{aligned}
& D_{1}=\frac{\left(89.50^{0.12}\right)\left(87.00^{0.14}\right)\left(87.00^{0.11}\right)\left(87.00^{0.12}\right)\left(87.00^{0.13}\right)\left(87.00^{0.13}\right)\left(87.00^{0.13}\right)\left(87.00^{0.12}\right)}{4}=22.02 \\
& D_{2}=\frac{\left(7.50^{0.12}\right)\left(92.50^{0.14}\right)\left(7.50^{0.11}\right)\left(7.50^{0.12}\right)\left(7.50^{0.13}\right)\left(7.50^{0.13}\right)\left(7.50^{0.13}\right)\left(7.50^{0.12}\right)}{4}=2.68 \\
& D_{3}=\frac{\left(8.50^{0.12}\right)\left(8.50^{0.14}\right)\left(91.50^{0.11}\right)\left(8.50^{0.12}\right)\left(8.50^{0.13}\right)\left(8.50^{0.13}\right)\left(8.50^{0.13}\right)\left(8.50^{0.12}\right)}{4}=2.79 \\
& D_{4}=\frac{\left(9.50^{0.12}\right)\left(9.50^{0.14}\right)\left(9.50^{0.11}\right)\left(90.50^{0.12}\right)\left(9.50^{0.13}\right)\left(9.50^{0.13}\right)\left(9.50^{0.13}\right)\left(9.50^{0.12}\right)}{4}=3.13 \\
& D_{5}=\frac{\left(87.00^{0.12}\right)\left(87.00^{0.14}\right)\left(87.00^{0.11}\right)\left(87.00^{0.12}\right)\left(87.50^{0.13}\right)\left(87.00^{0.13}\right)\left(87.00^{0.13}\right)\left(87.00^{0.12}\right)}{4}=21.96
\end{aligned}
$$


$D_{6}=\frac{\left(84.00^{0.12}\right)\left(84.00^{0.14}\right)\left(84.00^{0.11}\right)\left(84.00^{0.12}\right)\left(84.00^{0.13}\right)\left(86.00^{0.13}\right)\left(84.00^{0.13}\right)\left(84.00^{0.12}\right)}{4}=21.25$

$D_{7}=\frac{\left(83.00^{0.12}\right)\left(83.00^{0.14}\right)\left(83.00^{0.11}\right)\left(83.00^{0.12}\right)\left(83.00^{0.13}\right)\left(83.00^{0.13}\right)\left(84.00^{0.13}\right)\left(83.00^{0.12}\right)}{4}=20.79$

$D_{8}=\frac{\left(9.50^{0.12}\right)\left(9.50^{0.14}\right)\left(9.50^{0.11}\right)\left(9.50^{0.12}\right)\left(9.50^{0.13}\right)\left(9.50^{0.13}\right)\left(9.50^{0.13}\right)\left(90.50^{0.12}\right)}{4}=3.13$

From the vector-D results for normalization of the positive inequality scores obtained previously, then the Vector-R calculation process can be carried out to determine the positive inequality. That Vector-R calculation process for positive inequality completely can be seen as follows:

$$
\begin{aligned}
& R_{1}=\frac{D_{1}}{D_{1}+D_{2}+D_{3}+D_{4}+D_{5}+D_{6}+D_{7}+D_{8}}=\frac{3.41}{3.41+23.44+23.42+23.39+4.02+4.43+5.02+22.94}=0.0310 \\
& R_{2}=\frac{D_{2}}{D_{1}+D_{2}+D_{3}+D_{4}+D_{5}+D_{6}+D_{7}+D_{8}}=\frac{23.44}{3.41+23.44+23.42+23.39+4.02+4.43+5.02+22.94}=0.2130 \\
& R_{3}=\frac{D_{3}}{D_{1}+D_{2}+D_{3}+D_{4}+D_{5}+D_{6}+D_{7}+D_{8}}=\frac{23.42}{3.41+23.44+23.42+23.39+4.02+4.43+5.02+22.94}=0.2128 \\
& R_{4}=\frac{D_{4}}{D_{1}+D_{2}+D_{3}+D_{4}+D_{5}+D_{6}+D_{7}+D_{8}}=\frac{23.39}{3.41+23.44+23.42+23.39+4.02+4.43+5.02+22.94}=0.2124 \\
& R_{5}=\frac{D_{5}}{D_{1}+D_{2}+D_{3}+D_{4}+D_{5}+D_{6}+D_{7}+D_{8}}=\frac{4.02}{3.41+23.44+23.42+23.39+4.02+4.43+5.02+22.94}=0.0365 \\
& R_{6}=\frac{D_{6}}{D_{1}+D_{2}+D_{3}+D_{4}+D_{5}+D_{6}+D_{7}+D_{8}}=\frac{4.43}{3.41+23.44+23.42+23.39+4.02+4.43+5.02+22.94}=0.0403 \\
& R_{7}=\frac{D_{7}}{D_{1}+D_{2}+D_{3}+D_{4}+D_{5}+D_{6}+D_{7}+D_{8}}=\frac{5.02}{3.41+23.44+23.42+23.39+4.02+4.43+5.02+22.94}=0.0456
\end{aligned}
$$

From the vector-D results for normalization of the negative inequality scores obtained previously, then the Vector-R calculation process can be carried out to determine the negative inequality. That Vector- $\mathrm{R}$ calculation process for negative inequality completely can be seen as follows:

$$
\begin{aligned}
& R_{1}=\frac{D_{1}}{D_{1}+D_{2}+D_{3}+D_{4}+D_{5}+D_{6}+D_{7}+D_{8}}=\frac{22.02}{22.02+2.68+2.79+3.13+21.96+21.25+20.97+3.13}=0.2249 \\
& R_{2}=\frac{D_{2}}{D_{1}+D_{2}+D_{3}+D_{4}+D_{5}+D_{6}+D_{7}+D_{8}}=\frac{2.68}{22.02+2.68+2.79+3.13+21.96+21.25+20.97+3.13}=0.0274 \\
& R_{3}=\frac{D_{3}}{D_{1}+D_{2}+D_{3}+D_{4}+D_{5}+D_{6}+D_{7}+D_{8}}=\frac{2.79}{22.02+2.68+2.79+3.13+21.96+21.25+20.97+3.13}=0.0285 \\
& R_{4}=\frac{D_{4}}{D_{1}+D_{2}+D_{3}+D_{4}+D_{5}+D_{6}+D_{7}+D_{8}}=\frac{3.13}{22.02+2.68+2.79+3.13+21.96+21.25+20.97+3.13}=0.0319 \\
& R_{5}=\frac{D_{5}}{D_{1}+D_{2}+D_{3}+D_{4}+D_{5}+D_{6}+D_{7}+D_{8}}=\frac{21.96}{22.02+2.68+2.79+3.13+21.96+21.25+20.97+3.13}=0.2243 \\
& R_{6}=\frac{D_{6}}{D_{1}+D_{2}+D_{3}+D_{4}+D_{5}+D_{6}+D_{7}+D_{8}}=\frac{21.25}{22.02+2.68+2.79+3.13+21.96+21.25+20.97+3.13}=0.2170 \\
& R_{7}=\frac{D_{7}}{D_{1}+D_{2}+D_{3}+D_{4}+D_{5}+D_{6}+D_{7}+D_{8}}=\frac{20.97}{22.02+2.68+2.79+3.13+21.96+21.25+20.97+3.13}=0.2141 \\
& R_{8}=\frac{D_{8}}{D_{1}+D_{2}+D_{3}+D_{4}+D_{5}+D_{6}+D_{7}+D_{8}}=\frac{3.13}{22.02+2.68+2.79+3.13+21.96+21.25+20.97+3.13}=0.0319
\end{aligned}
$$

Based on the results of the Vector-R for determining positive inequality that had been obtained previously, then ranking is carried out to obtain the aspects or alternatives that become the most dominant positive inequality. The results of the positive inequality ranking can be seen in Table 14. 
Table 14. Results of positive inequality ranking

\begin{tabular}{ccccccccc}
\hline Ranking & 1 & 2 & 3 & 4 & 5 & 6 & 7 & 8 \\
Vector-R & $\mathrm{R}_{2}$ & $\mathrm{R}_{3}$ & $\mathrm{R}_{4}$ & $\mathrm{R}_{8}$ & $\mathrm{R}_{7}$ & $\mathrm{R}_{6}$ & $\mathrm{R}_{5}$ & $\mathrm{R}_{1}$ \\
Scores & 0.2130 & 0.2128 & 0.2124 & 0.2084 & 0.0456 & 0.0403 & 0.0365 & 0.0310 \\
Alternatives & $\mathrm{A} 2$ & $\mathrm{~A} 3$ & $\mathrm{~A} 4$ & $\mathrm{~A} 8$ & $\mathrm{~A} 7$ & $\mathrm{~A} 6$ & $\mathrm{~A} 5$ & $\mathrm{~A} 1$ \\
\hline
\end{tabular}

Based on the results of the Vector-R for determining negative inequality that had been obtained previously, then ranking is carried out to obtain the aspects or alternatives that become the most dominant negative inequality. The results of the negative inequality ranking can be seen in Table 15.

Table 15. Results of negative inequality ranking

\begin{tabular}{ccccccccc}
\hline Ranking & 1 & 2 & 3 & 4 & 5 & 6 & 7 & 8 \\
Vector-R & $\mathrm{R}_{1}$ & $\mathrm{R}_{5}$ & $\mathrm{R}_{6}$ & $\mathrm{R}_{7}$ & $\mathrm{R}_{4}$ & $\mathrm{R}_{8}$ & $\mathrm{R}_{3}$ & $\mathrm{R}_{2}$ \\
Scores & 0.2249 & 0.2243 & 0.2170 & 0.2141 & 0.0319 & 0.0319 & 0.0285 & 0.0274 \\
Alternatives & $\mathrm{A} 1$ & $\mathrm{~A} 5$ & $\mathrm{~A} 6$ & $\mathrm{~A} 7$ & $\mathrm{~A} 4$ & $\mathrm{~A} 8$ & $\mathrm{~A} 3$ & $\mathrm{~A} 2$ \\
\hline
\end{tabular}

Based on the data in Table 8, the data in Table 14, and the data in Table 15, analysis can be carried out based on the Analysis component of the DIVAYANA model. The results of the positive inequality ranking in Table 14 showed that alternative- 2 was the alternative that becomes the most dominant positive inequality. This was because alternative- 2 had the highest score when compared to other alternatives. When compared with the data in Table 7, the selection of alternative- 2 as the most dominant positive inequality had proven that the agreement of the arguments expressed by education experts- 2 had been proven valid and correct. This was because alternative- 2 showed conformity with the arguments of the education expert-2, which in principle indicates an adjustment to school regulations that refer to government policies.

The results of the negative inequality ranking in Table 15 showed that alternative- 1 was the alternative that becomes the most dominant negative inequality. This was because alternative-1 had the highest score when compared to other alternatives. When compared with the data in Table 7, the selection of alternative-1 as the most dominant negative inequality had proven that the agreement of the arguments expressed by the education expert-1 had been proven valid and correct. This was because alternative- 1 showed conformity with the arguments of the education expert-1, which in principle showed that efforts to disseminate the policy of Merdeka Belajar to all school communities had not optimal yet.

The actualization process of alternatives or aspects that were the most dominant positive and negative inequalities were guided by the actualization component in the DIVAYANA model. The actualization process of the alternative or aspect that was the most dominant positive inequality was carried out by maintaining the existence of that aspect in supporting the success of flipped learning implementation at IT vocational schools in Bali. The actualization process of the alternative or aspect that was the most dominant negative inequality was carried out by revising or improving that aspect so that the flipped learning implementation becomes more optimal.

At the Stage of Revision of Initial Trials were conducted revision activities toward the evaluation model design. The revisions were made based on some suggestions given by respondents in the initial trials shown in Table 12 previously. The revision results can be seen in Figure 3. The final design shown in Figure 3 was evidence of the answers to several suggestions shown earlier in Table 11. Question of respondent-4 had been answered by displaying Equation (1), Equation (2), and Equation (3) of the DIVAYANA formula in the final design. Question of respondent-8 had been answered by the existence of the boundary line that distinguishes the process in the DIVAYANA model and the Discrepancy model. Question of Respondent-34 had been answered by showing different colours between the DIVAYANA model components and the Discrepancy model components. Question of respondent-38 had been answered by showing the concept of Daiwi Sampad as the basis for determining positive inequality and the concept of Asuri Sampad as the basis for determining negative inequality. Question of respondent-40 had been answered by showing capital letters and in bold at the beginning of each component name of the DIVAYANA evaluation model.

If we look at the average percentage of quality shown earlier in Table 10 and the five's scale category, then this model design was in a good category. This evident from the percentage was $88.25 \%$ located in the $80 \%$ to $89 \%$ score range when viewed from the five's scale category. The results of this study had generally succeeded in answering the obstacles of Zhao \& Sun's research in 2018 [3], Ha et al.'s research in 2019 [6], Sickle's research in 2016 [16], Vogelsang \& Hoppe's research in 2018 [17], Shiau et al.'s research in 2018 [18], Bergfjord \& Heggernes's research in 2016 [19] by showing the alternatives or aspects were the most dominant of positive and negative inequalities in the flipped learning implementation. 


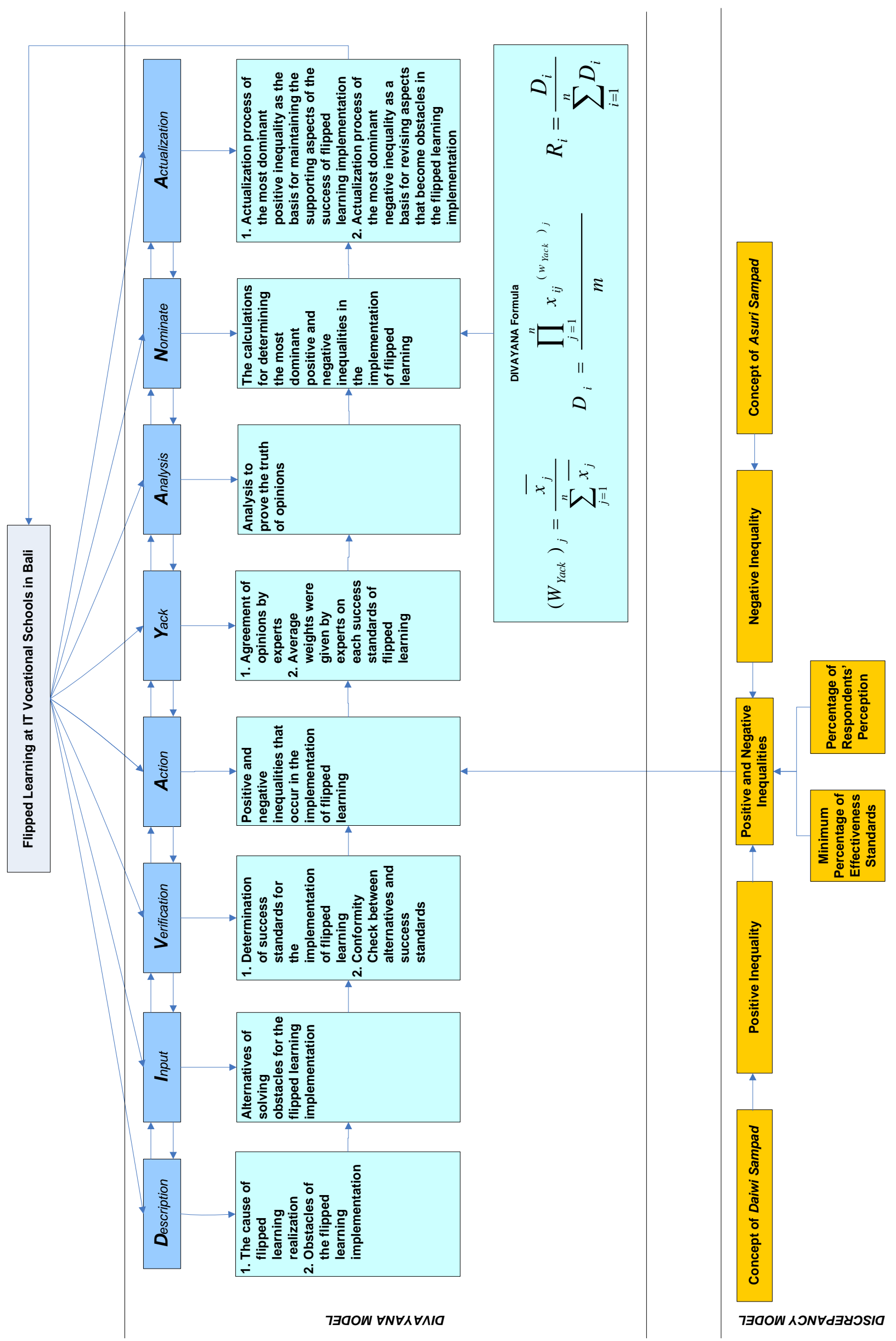

Figure 3. The final design of the DIVAYANA model based on Discrepancy Daiwi Asuri Sampad 
The findings of this research showed the existence of an innovative evaluation model as an innovation in the field of IT education evaluation. This evaluation model combines the general concept of educational evaluation, the concept of religion and local culture, and the concept of artificial intelligence in the field of information technology to produce accurate recommendations in solving problems in the field of educational evaluation. This is reinforced by the results of previous research which in principle also found innovative evaluation models by integrating various evaluation concepts, culture, and other fields of science [27-37]. The implications of this new evaluation model design for evaluation activities, especially in the field of IT education are being able to show accurate recommendations as evaluation results of the flipped learning implementation. The recommendations refer to the calculation results to determine the most dominant aspects of positive and negative inequalities in the flipped learning implementation.

The strength of this research will be seen when compared with the limitations found in other studies. The limitations of Sholeh \& Trihantoyo's research [38] were that it had not shown most dominant aspects of positive and negative inequalities affect the effectiveness of the teachers' duties implementation in their preparation as headmaster. The limitations of Setiawan et al.'s research [39] were that it had not shown in detail the dominant aspects that need improvement in supporting the implementation of the IHES (Integrated and Holistic Education System) program. The limitations of Aw's research [40] were that it had not shown the dominant aspects that need to be maintained in realizing the effectiveness of public relations programs in encouraging synergistic collaboration between industry and schools. The limitations of Aliyyah et al.'s research [41] were that it had not shown the most dominant aspects of positive and negative inequalities that affect the smooth implementation of the education scholarship program for students in Indonesia. The limitations of Mauliate et al.'s research [42] were that it had not shown in detail the dominant aspects that need to be maintained in supporting the effectiveness of the lesson plan of English language learning in junior high school. The limitations of Sithole \& Mafa's research [43] were that it had not shown the steps to determine the most dominant aspects of positive and negative inequalities in the Discrepancy evaluation model used to assess the theory and practice of inclusive education. The limitations of Ndayizeye's research [44] were that it had not shown in detail explanation regarding the use of the Discrepancy evaluation model to determine dominant aspects that become the positive and negative inequalities that cause gaps in the student pragmatic learning assessment process. The limitations of Herawati et al.'s research [45] were that it had not shown the most dominant aspects that become the positive and negative inequalities in supporting the effectiveness of the implementation of policy on the education board. Based on some of the limitations of those studies, it appears that the strength of this research is can shows the design of a new evaluation model. An evaluation model equipped by facilities to determine the most dominant aspects of positive and negative inequalities supports the effectiveness of the ICT-based learning process.

If this research is compared with Divayana's research [8] and Divayana et al.'s research [9] previously, this research has similarities regarding the use of the DIVAYANA model stages. The stages of the DIVAYANA evaluation model were used as the basic foundation in this research and integrated with the Discrepancy model, the Asuri Sampad concept, and the Daiwi Sampad concept. When compared to previous studies, the difference of this research is the existence of data sources in the Action component of the DIVAYANA model. This shows that there are strengths and novelties in this research. The existence of data sources in the Action component in previous studies was obtained from the average percentage of the results of field tests conducted by respondents toward the implementation of ICT-based learning models. In this research, the existence of data sources in the Action component was obtained from the positive and negative inequalities scores that occur in the implementation of the ICT-based learning model. The positive and negative inequalities scores were obtained from the deviation between the percentage of respondents' perceptions and the minimum percentage of the effectiveness standards for implementing the ICT-based learning model. Those positive and negative inequalities scores become basic data that facilitates the calculation process in the DIVAYANA model to determine an accurate ranking so that it finally obtains the appropriate recommendations.

Besides those strengths, this research also has limitations. The limitations of this research are the results of the impact evaluation activities are not shown in detail. Even though, it had conducted the actual implementation toward alternatives or aspects that become the most dominant positive and negative inequalities in the flipped learning implementation.

\section{4- Conclusion}

Quality of the DIVAYANA evaluation model design based on Discrepancy Daiwi Asuri Sampad is a good categorized. This design can be used as a reference for the design of innovative evaluation models in the field of educational evaluation in general and specifically in the field of IT education. This model design can be used to show an overview of the alternatives or aspects that become the most dominant positive and negative inequalities to realize the effectiveness of the flipped learning implementation at IT vocational schools in Bali. The most dominant positive and negative inequalities scores can be easily determined by referring to the three equations owned by the DIVAYANA formula. The interpretation of the positive inequality score refers to the Daiwi Sampad concept, while the interpretation of the negative inequality score refers to the Asuri Sampad concept. This evaluation model design is not limited to only providing an overview of determining the aspects which are the most dominant positive and negative 
inequalities in influencing the flipped learning effectiveness. However, this evaluation model design can also be used to evaluate the effectiveness of other ICT-based learning models. This evaluation model design can be implemented into an evaluation application in the form of software. Operation of evaluation applications can be in the form of desktop-based standalone or web-based online applications. This evaluation model design can not only be used by education experts and evaluators but can also be used by all teachers at IT vocational schools and education observers who are steeped in educational evaluation. The development of this evaluation model design is not limited to modifications between the DIVAYANA evaluation model, the Discrepancy model, the Daiwi Sampad and Asuri Sampad concepts. However, in the future, it is recommended to apply the artificial intelligence concept to this evaluation model design so that the recommendation results will be more accurate. Future work that can be done to solve the obstacles found in this research is to specifically evaluate the impact on the real implementation process of the alternatives or aspects that becomes the most dominant positive and negative inequalities.

\section{5- Declarations}

\section{5-1-Author Contributions}

D.G.H.D.: Conceptualization, methodology, data curation, formal analysis, investigation, writing-original draft, writing-reviewing and editing; I.P.W.A.: Data curation and formal analysis; A.A.: Data curation and formal analysis. All authors have read and agreed to the published version of the manuscript.

\section{5-2-Data Availability Statement}

The data presented in this study are available in article.

\section{5-3- Funding}

The authors received financial support based on Research Grant Number: 153/UN48.16/LT/2021 from the Directorate General of Higher Education, Research, and Technology of Ministry of Education, Culture, Research, and Technology of the Republic of Indonesia for the research, authorship, and/or publication of this article.

\section{5-4-Acknowledgements}

The authors also express their gratitude to the Rector of Universitas Pendidikan Ganesha and Chair of the Research and Community Service Institute of Universitas Pendidikan Ganesha, who give the opportunity and permission to the authors for carrying out this research.

\section{5-5- Conflicts of Interest}

The authors declare that there is no conflict of interests regarding the publication of this manuscript. In addition, the ethical issues, including plagiarism, informed consent, misconduct, data fabrication and/or falsification, double publication and/or submission, and redundancies have been completely observed by the authors.

\section{6- References}

[1] Antonopoulou, H., Halkiopoulos, C., Barlou, O., \& Beligiannis, G. N. (2021). Transformational Leadership and Digital Skills in Higher Education Institutes: During the Covid-19 Pandemic. Emerging Science Journal, 5(1), 1-15. doi:10.28991/esj-202101252.

[2] Handayani, D. P., Sutarno, H., \& Wihardi, Y. (2018). Design E-learning with Flipped Learning Model to Improve Layout Understanding the Concepts Basic of the Loop Control Structure. Journal of Physics: Conference Series, 1013, 1-8. doi:10.1088/1742-6596/1013/1/012100.

[3] Zhao, A., \& Sun, C. (2018). Study on the Evaluation System of Flipped Classroom Teaching in Colleges and Universities. Advances in Social Science, Education and Humanities Research, 221, 155-159. doi:10.2991/ceed-18.2018.32.

[4] Wozny, N., Balser, C., \& Ives, D. (2018). Evaluating the Flipped Classroom: A Randomized Controlled Trial. Journal of Economic Education, 49(2), 115-129. doi:10.1080/00220485.2018.1438860.

[5] Kim, S. (2018). How to Evaluate Learning in a Flipped Learning. Journal of Educational Evaluation for Health Professions, 15(21), 1-2. doi:10.3352/jeehp.2018.15.21.

[6] Ha, A. S., O’Reilly, J., Ng, J. Y. Y., \& Zhang, J. H. (2019). Evaluating the Flipped Classroom Approach in Asian Higher Education: Perspectives from Students and Teachers. Cogent Education, 6(1), 1-12. doi:10.1080/2331186X.2019.1638147.

[7] Gómez-Carrasco, C. J., Monteagudo-Fernández, J., Moreno-Vera, J. R., \& Sainz-Gómez, M. (2020). Evaluation of a Gamification and Flipped-Classroom Program Used in Teacher Training: Perception of Learning and Outcome. PLOS ONE, 15(7), 1-19. doi:10.1371/journal.pone.0236083. 
[8] Divayana, D. G. H. (2020). Utilization of DIVAYANA Formula in Evaluating of Suitable Platforms for Online Learning in the Social Distancing. International Journal of Interactive Mobile Technologies, 14(20), 50-75. doi:10.3991/IJIM.V14I20.15787.

[9] Divayana, D. G. H., Suyasa, P. W. A., \& Widiartini, N. K. (2021). An Innovative Model as Evaluation Model for Information Technology-Based Learning at ICT Vocational Schools. Heliyon, 7(2), 1-13. doi:10.1016/j.heliyon.2021.e06347.

[10] Naswardi. (2017). Evaluation of Community Services and Mediation Services Infringement of Children's Rights in the Commission of Indonesian Child Protection. International Journal of Human Capital Management, 1(2), 37-44. doi:10.21009/ijhcm.01.02.05.

[11] Jayanta, I. N. L., Suryantari, K. D., \& Sumantri, M. (2017). An Analysis of Discrepancy between the Lesson Plan and the Implementation of Curriculum 2013 in Teaching and Learning Process in SD Negeri 4 Kaliuntu. Journal of Education Research and Evaluation, 1(2), 73-81. doi:10.23887/jere.v1i2.9839.

[12] Sulistyawati. (2017). Balinese 'Umah' Architecture as Implementation of Hindu Religion in Bali. International Journal of Multidisciplinary Educational Research, 6(11-4), 72-92.

[13] Suparta, N., Suarka, I. N., Tantra, D. K., \& Bidura, I. G. N. G. (2019). Wewalungan Ritual of Hindu's Tawur Tabuh Gentuh at Besakih Temple, Bali, Indonesia. International Journal of Multidisciplinary Approach and Studies, 6(4), 80-91.

[14] Putrayasa, I. B. (2017). Literature as Media Education Nation Character Values. International Journal of Linguistics, Literature, and Culture, 3(3), 1-9. doi:10.21744/ijllc.v3i3.443.

[15] Suwardani, N. P., Paramartha, W., \& Indiani, N. M. (2019). Formatting of Religious Attitude of Hindu Bali Youth in the Context of Religion Conversion (Ethnopedagogy Study in Taro Tegalalang Village, Gianyar). Vidyottama Sanatana: International Journal of Hindu Science and Religious Studies, 3(2), 240-249. doi:10.25078/ijhsrs.v3i2.1004.

[16] Sickle, J. R. V. (2016). Discrepancies between Student Perception and Achievement of Learning Outcomes in a Flipped Classroom. Journal of the Scholarship of Teaching and Learning, 16(2), 29-38. doi:10.14434/josotl.v16i2.19216.

[17] Vogelsang, K., \& Hoppe, U. (2018). Development of an Evaluation for Flipped Classroom Courses. MKWI 2018 - Multi Konferenz Wirtschafts Informatik, 2018-March, 821-832.

[18] Shiau, S., Kahn, L. G., Platt, J., Li, C., Guzman, J. T., Kornhauser, Z. G., Keyes, K. M., \& Martins, S. S. (2018). Evaluation of a Flipped Classroom Approach to Learning Introductory Epidemiology. BMC Medical Education, 18(1), 1-8. doi:10.1186/s12909-018-1150-1.

[19] Bergfjord, O. J., \& Heggernes, T. (2016). Evaluation of a "Flipped Classroom" Approach in Management Education. Journal of University Teaching and Learning Practice, 13(5), 1-13. doi:10.53761/1.13.5.6.

[20] Hendikawati, P., Zahid, M. Z., \& Arifudin, R. (2019). Android-Based Computer Assisted Instruction Development as a Learning Resource for Supporting Self-Regulated Learning. International Journal of Instruction, 12(3), $389-404$. doi:10.29333/iji.2019.12324a.

[21] Wibawa, B., \& Paidi. (2019). The Development of Blended Learning Based on Handphone for Computer System Subject on XI Grade of SMKN 1 Bengkulu City. Humanities and Social Sciences Reviews, 7(3), 497-502. doi:10.18510/hssr.2019.7373.

[22] Martín, J. C., Román, C., \& Gonzaga, C. (2018). How Different N-Point Likert Scales Affect the Measurement of Satisfaction in Academic Conferences. International Journal for Quality Research, 12(2), 421-440. doi:10.18421/IJQR12.02-08.

[23] Dalimunte, M., \& Salmiah, M. (2019). Students' Ability at Changing Direct into Indirect Speech and Indirect into Direct Speech. Budapest International Research and Critics Institute (BIRCI-Journal): Humanities and Social Sciences, 2(2), 178185. doi:10.33258/birci.v2i2.249.

[24] Sari, S. A., \& Rezeki, Y. S. (2019). The Development of an Ingenious Circuit Based on Chemo-Edutainment Learning. International Journal of Educational Research Review, 4(1), 15-25. doi:10.24331/ijere.467078.

[25] Sugiharni, G. A. D. (2021). Instrument Development Design for Metacognitive Determination in Calculus Problem Solving. Journal of Physics: Conference Series, 1918, 1-6. doi:10.1088/1742-6596/1918/4/042061.

[26] Sari, L. Y., Susanti, D., Fitriani, V., \& Supriatno, B. (2020). How to Validity Handbook in Introduction and Laboratory Techniques Oriented PBL. International Journal of Progressive Sciences and Technologies, 19(1), $250-254$. doi:10.52155/ijpsat.v19.1.1625.

[27] Tusar, T., \& Filipic, B. (2015). Visualization of Pareto Front Approximations in Evolutionary Multiobjective Optimization: A Critical Review and the Prosection Method. IEEE Transactions on Evolutionary Computation, 19(2), $225-245$. doi:10.1109/TEVC.2014.2313407. 
[28] Huda, M. Q., \& Hussin, H. (2016). Evaluation Model of Information Technology Innovation Effectiveness Case of Higher Education Institutions in Indonesia. 2016 International Conference on Informatics and Computing, ICIC 2016, 1-6. doi:10.1109/IAC.2016.7905719.

[29] Suarez, E. G, \& Toro, R. M. (2018). Evaluación del desempeño docente: Preparación para el aprendizaje de los estudiantes en el Marco de Buen Desempeño Docente (Teaching Performance Evaluation Model: Preparation for Student Learning within the Framework for Teacher Good Performance). Propósitos y Representaciones, 6(2), 431-452. doi:10.20511/pyr2018.v6n2.236.

[30] Anh, V. T. K. (2018). Evaluation Models in Educational Program: Strengths and Weaknesses. VNU Journal of Foreign Studies, 34(2), 140-150. doi:10.25073/2525-2445/vnufs.4252.

[31] Vargas, J., Moreno, M. C., \& Isaza, L. (2018). Evaluation Model Based on Artificial Neural Networks for the Use and Appropriation of Information and Communication Technologies in Higher Education Teachers. International Journal of Applied Engineering Research, 13(12), 10169-10174.

[32] Sohrabi, Z., Keshavarzi, M. H., Pourbairamian, G., Ramezani, G., \& Ghanavati, S. (2020). Flipped Classroom \& Kirkpatrick: Steps Toward Innovation in Education \& Evaluation. Biomedical Journal of Scientific \& Technical Research, 29(3), 2248922494. doi:10.26717/bjstr.2020.29.004811.

[33] Gan, Q. (2020). Research on the Emotional Cognitive Evaluation Model Based on Artificial Neural Network. E3S Web of Conferences, 145, 1-5. doi:10.1051/e3sconf/202014501040.

[34] Khatibi, V., Keramati, A., \& Shirazi, F. (2020). Deployment of a Business Intelligence Model to Evaluate Iranian National Higher Education. Social Sciences \& Humanities Open, 2(1), 1-9. doi:10.1016/j.ssaho.2020.100056.

[35] Pereira, C.A., Araujo, J. F. F. E., \& Machado-Taylor, M. D. L. (2018). The Brazilian Higher Education Evaluation Model: "SINAES" Sui Generis?. International Journal of Educational Development, 61, 5-15. doi:10.1016/j.ijedudev.2017.11.007.

[36] Wakitani, S., Yamamoto, T., Morishige, C., Adachi, T., Harada, Y., \& Muraoka, T. (2019). Practice and Evaluation of Model Based Development (MBD) Education. IFAC-PapersOnLine, 52(9), 206-211. doi:10.1016/j.ifacol.2019.08.197.

[37] Germán-Salló, Z., Grif, H.Ş., \& Gligor, A. (2017). An Evaluation Model for Functionality Analysis of Remote Laboratories and Simulations in Engineering Education. Procedia Engineering, 181, 1058-1063. doi:10.1016/j.proeng.2017.02.507.

[38] Sholeh, M., \& Trihantoyo, S. (2020). Evaluating Teachers' Assignment Implementation as School Principals Preparation Program in Indonesia. Advances in Social Science, Education and Humanities Research, 387, 151-154. doi:10.2991/icei19.2019.36

[39] Setiawan, I., Madhakomala, D., \& Sujanto, B. (2019). The Evaluation of Integrated and Holistic Education System (Ihes) Program in Gema Nurani Integrated and Holistic Islamic Elementary School, Bekasi, West Java. Universal Journal of Educational Research, 7(9A), 162-170. doi:10.13189/ujer.2019.071619.

[40] Aw, S. (2018). An Evaluation of a Public Relations Program in Promoting Synergistic Cooperation between Schools and Industries. Problems and Perspectives in Management, 16(4), 353-364. doi:10.21511/ppm.16(4).2018.29.

[41] Aliyyah, R. R., Rosyidi, U., \& Yazid, R. (2019). An Evaluative Study of an Education Scholarship Program (Bidik Misi) for Students in Indonesia. Journal of Physics: Conference Series, 1175, 1-6. doi:10.1088/1742-6596/1175/1/012171.

[42] Mauliate, H. D., Rahmat, A., \& Wachidah, S. (2019). Evaluation the Lesson Plan of English Language Learning in Junior High School, Seraphine Bakti Utama West Jakarta. International Journal of Scientific Research and Management, 7(7), $1078-1086$. doi:10.18535/ijsrm/v7i7.el02.

[43] Sithole, E. S. M., \& Mafa, O. (2017). An Assessment of the Theory and Practice of Inclusive Education, with Special Reference to Secondary Teacher Education in Zimbabwe. International Journal of Science and Research (IJSR), 6(4), 12301241. doi:10.21275/ART20172402.

[44] Ndayizeye, O. (2017). Discrepancies in Assessing Undergraduates' Pragmatics Learning. Research and Evaluation in Education, 3(2), 133-143. doi:10.21831/reid.v3i2.14487.

[45] Herawati, E. S. B., Suryadi, \& Sujanto, B. (2019). Evaluating the Implementation of Policy on Education Board. International Journal for Educational and Vocational Studies, 1(3), 236-243. doi:10.29103/ijevs.v1i3.1584. 